\title{
Contemporary Perspectives on Risk Perceptions, Health-Protective Behaviors, and Control of Emerging Infectious Diseases
}

\author{
Elaine Vaughan
}

Published online: 21 April 2011

(C) International Society of Behavioral Medicine 2011

Emerging and re-emerging infectious diseases present a significant and growing threat to human health within individual countries and globally [1-4]. Of some concern are evolving or novel strains of infectious disease agents where human immunity may be limited including the highly pathogenic avian influenza $\mathrm{A}(\mathrm{H} 5 \mathrm{~N} 1)$, subtypes of influenza A(H1N1) (associated with the deadly 1918 and the 2009-2010 pandemics), the virus responsible for severe acute respiratory syndrome, and multidrug-resistant bacterial strains $[1,2,5,6]$. Local or widespread outbreaks, including influenza pandemics, are largely unpredictable and periodically emerge with a potential for extreme public health, economic, and social consequences [2, 3, 6-9]. Importantly, human behavior plays a major role in the spread of infectious diseases $[6,10]$. Public health strategies to reduce an outbreak's impact rely heavily on prompting timely individual actions, including decisions about vaccines and other healthprotective behaviors [2, 6, 11]. However, evidence from psychology, behavioral medicine, and public health reveals that many at-risk individuals are reluctant, refuse, or are unable to act in a timely manner despite strong precaution adoption recommendations during a confirmed public health emergency or infectious disease outbreak [8, 10, 12-14].

Individuals' failure or inability to adopt prescribed precautionary behaviors is an anticipated major challenge for minimization of mortality and morbidity during an infectious disease epidemic or pandemic $[6,15,16]$. Furthermore, precaution adoption is often unequal across subpopulations within a country and frequently varies across

E. Vaughan $(\bowtie)$

Department of Psychology and Social Behavior,

University of California,

Irvine, CA, USA

e-mail: evaughan@uci.edu segments of society defined by race or ethnicity, socioeconomic circumstances, geography, education, and other determinants of social position [3,12, 13, 16-21]. Providing the public with facts about an emerging infectious disease episode is a necessary but insufficient step for containment. Public knowledge about infectious disease risk, experts' views about effectiveness of health-protective actions, or access to pharmaceutical interventions (e.g., vaccines) will not be the sole or even most significant determinants of health-protective behaviors during an emerging episode [22-23]. Risk perceptions and subjective appraisals of the situation greatly influence whether and when a recommended protective action is likely to be adopted [24-27]. Health and risk communications during an outbreak must address those perceptions, life circumstances, and other forces that may be incompatible with suggested behavioral change [13, 14, 18, 19, 28]. This requires an understanding of the psychology of risk perceptions and precaution adoption, and the influence of social, economic, and cultural contexts within which individual-level responses are embedded. Without this informed approach, planned public health interventions will have limited success $[21,22,29]$.

Over the past two decades, significant progress and discoveries have been made in understanding risk perceptions, their relationship with health-protective behaviors, and central role in public health efforts to control emerging infectious diseases $[25,30-32]$. Theoretical perspectives and empirical research increasingly are more comprehensive in defining what contributes to risk perceptions, situation awareness, and risk-reduction behaviors during an emerging infectious disease incident. Traditional psychological models of precaution adoption or health behavior change have been used to explain health-protective actions during an infectious disease threat, and these mostly have 
emphasized cognitive dimensions of risk perceptions (e.g., perceived susceptibility, perceived severity of the threat) $[25$, 33-38], including appraisals of the safety, effectiveness, and necessity of recommended actions $[14,34,36,39]$. The majority of these models consider responses in isolation of prior experiences and life circumstances that affect how individuals evaluate risk information $[14,16]$. In contrast, more contemporary perspectives also take into account broader influences such as emotions, social processes, cultural values or beliefs, socioeconomic conditions, trust in public health authorities, and the timing or characteristics of events associated with the infectious disease outbreak. Newer perspectives build on traditional models in several ways and consider the strong association between certain emotions (e.g., regret, fear, worry) and health-protective behaviors [15, 27, 40-43], the persistent social disparities in the adoption of precautionary actions and the effectiveness of risk-reduction policies [7, 12-14, 41, 44], the effects of cultural and social processes on perceptions and behaviors [7, 16, 44-46], and the dynamics of infectious disease episodes that may prompt modifications in responses as individuals react to situational developments $[13,14,22,47-49]$. For example, as an infectious disease event progresses, changes can occur in profiles of those most vulnerable to infection or medical complications, proximity to or personal knowledge of affected individuals, seriousness of average or extreme cases, and perceptions of social norms regarding risk or recommended actions $[13,22,25,47-50]$.

This special issue of $I J B M$ includes five empirical articles that reflect these more contemporary views of infectious disease risk perceptions and their relationship with precautionary behavior. Several articles also demonstrate the challenges of controlling infectious diseases across diverse populations. The first article by Goodwin et al. [51] considers associations between worry about a pandemic influenza threat and behavioral responses. The paper reports results of an online questionnaire study of predictors of early reactions to the $2009 \mathrm{H} 1 \mathrm{~N} 1$ pandemic among European residents of Portuguese, British, or Finnish background. Goodwin et al. found an association between personal worry about $\mathrm{H} 1 \mathrm{~N} 1$ and avoidance and preparatory behaviors, and that those who held certain cultural values and beliefs that family and friends worried about the influenza threat were more concerned about personal risk and risk to family members from the outbreak. The significant association between personal worry and judgments about the level of worry of significant others suggests the potential importance of social processes in how individuals react to an emerging infectious disease pandemic. The authors also noted that their study occurred early in the pandemic and that responses could be time sensitive.
In the second article of this series, Liao and colleagues [52] also adopt a broader perspective on contributors to individual-level responses during an infectious disease outbreak. The authors describe a study of health-protective actions (non-pharmaceutical) and consider the relative role of worry and cognitive factors in the adoption of personal precautionary behaviors. Liao et al. examined strength of associations between trust in formal and informal information sources, knowledge, perceived effectiveness of precautionary behaviors, perceived risk susceptibility, worry and precautionary practices, and used structural equation modeling to identify pathways that link these concepts. Two independent survey datasets were used to test associations and represented different infectious disease circumstances. Samples were drawn from the general Hong Kong population, but the first survey focused on avian influenza $\mathrm{A}(\mathrm{H} 5 \mathrm{~N} 1)$ responses during the epidemic's peak in Southeast Asia during late 2005 and early 2006, and the second measured responses during early stages of the 2009 influenza A(H1N1) pandemic. Survey data found support for the role of knowledge, trust in formal information sources, and perceived effectiveness of precautionary practices in the adoption of health-protective behaviors. Liao et al. also found that trust in formal information may influence behavior partially because it affects judgments about the effectiveness of personal precautionary actions. However, there were differences between the surveys in the association between worry and precautionary behaviors, and Liao and colleagues speculated that characteristics of an influenza outbreak (e.g., severity of cases) or the historical context of an emerging infectious disease could affect relationships among trust, risk perceptions, worry, and personal hygiene practices.

The third article by Wong [53] highlights the importance of considering broader social, cultural, and economic contexts of infectious disease control in multiethnic, multi-religious societies, and within medically underserved populations. This study examined behavioral intentions to receive a newly introduced vaccine to reduce the risk of human papillomavirus (HPV), a sexually transmitted infectious disease agent associated with cervical cancer. Wong considers possible challenges of HPV immunization in a population of ethnically diverse rural women in Malaysia where barriers to a successful immunization program not only include the availability and cost of the vaccine but also could include social and cultural factors, certain risk perceptions, and knowledge about HPV and vaccine benefits. Wong found that knowledge about HPV and the new vaccine was extremely low, and varied by education, age, relationship status (e.g., married or single), and ethnicity, with Chinese women less knowledgeable about HPV, risk factors for cervical cancer, and the vaccine than women from a Malay or Indian background. After 
interviewers provided information about HPV, the majority indicated an intention to receive the vaccine. However, a significant percentage still would refuse vaccination, and reasons included doubts about vaccine safety and effectiveness, embarrassment, and a low perception of risk from HPV. Wong noted that embarrassment was mentioned by many women in the study, but was much more likely to be a factor for Muslim women. Wong emphasized the importance of closing the knowledge gap about HPV in this diverse population but argued that efforts also should be made to address perceptions and social stigma that may limit vaccine acceptance and uptake.

The next article in this series by Wong and Sam [54] considered knowledge and risk perceptions as possible contributors to success or failure of control and containment strategies during an emerging infectious disease outbreak. Within multiethnic communities in Malaysia, the authors examined attitudes and knowledge about the 2009 H1N1 influenza outbreak soon after the WHO had declared a worldwide pandemic. This population-based interview study included diverse ethnic and sociodemographic groups and explored cultural and social variation in perceptions of H1N1 risk, knowledge, and the stigma associated with H1N1 infection. The study revealed ethnic and other sociodemographic differences in the prevalence of misconceptions about how H1N1 infection could occur and the mortality rate once infected. In addition, knowledge about the outbreak varied across sociodemographic groups with lower knowledge scores associated with being male, of Malay background (as opposed to Chinese or Indian), having less formal education and income, and residing in rural localities. Individuals tended to perceive themselves and family members as being at low risk for contracting H1N1 and were confident that they could prevent infection. Different sociodemographic groups varied in the likelihood of these perceptions. The results also confirmed the prevalence of influenza $\mathrm{A}(\mathrm{H} 1 \mathrm{~N} 1)$-related stigma among certain populations and ethnic differences in beliefs about the stigma associated with contracting H1N1. As the authors discussed, there may be different information needs, misconceptions, and concerns among diverse subpopulations within a country, and these could influence the success of containment efforts for an emerging infectious disease.

The final article in this series illustrates the value of understanding broader social circumstances of potentially affected populations when designing public health communication campaigns to contain an infectious disease outbreak. Within a sample of young adults in Karachi, Pakistan, Farid-ul-Hasnain and Krantz [55] conducted a population-based questionnaire study of risk factors for involuntarily leaving school or college and implications for awareness about HIV/AIDS and sexually transmitted diseases (STDs). Overall, there was low awareness of
STDs in this sample. However, the authors found that economic disadvantage, migrant residential status, and living in an extended family were associated with a greater likelihood of dropping out of school or college and that some of these individuals, specifically the young adult males, had even lower awareness rates and knowledge of HIV/AIDS and STDs than others. Although this crosssectional study cannot demonstrate a causal association between school dropout rates and levels of awareness of STDs, it provides a profile of a group of young adults where efforts to provide information about certain infectious diseases should be prioritized and life circumstances reflected in public health outreach strategies.

In summary, the five articles in this special series reflect newer "contextual" perspectives on relationships between risk perceptions, protective behaviors, and the control of emerging infectious diseases. Many public health strategies for containment and mitigation depend on a significant percentage of the population acting in prescribed ways to prevent infection and reduce disease transmission. This series suggests that infectious disease communications and policies must be responsive to perceptions, emotions, trust, knowledge, social stigma, and other barriers to behavioral change that may be present to different degrees in dissimilar social and cultural "environments." This special issue of $I J B M$ provides convincing evidence for the necessity of comprehensive frameworks to understand human behavior and decisions during an emerging infectious disease epidemic or pandemic.

\section{References}

1. Jones KE, Patel NG, Levy MA, Storeygard A, Balk D, Gittleman $\mathrm{JL}$, et al. Global trends in emerging infectious diseases. Nature. 2008;451:990-4.

2. Morens DM, Folkers GK, Fauci AS. The challenge of emerging and re-emerging infectious diseases. Nature. 2004;430:242-9.

3. World Health Organization. State of the world's vaccines and immunization. 3rd ed. Geneva: WHO Press; 2009.

4. Fauci A. Emerging and re-emerging infectious diseases: the perpetual challenge. Acad Med. 2005;80:1079-85.

5. Wallinga $J$, van Boven $M$, Lipsitch $M$. Optimizing infectious disease interventions during an emerging epidemic. Proc Natl Acad Sci USA. 2010;107:923-8.

6. World Health Organization. Pandemic influenza preparedness and response. Geneva: WHO Press; 2010.

7. Holmes BJ. Communicating about emerging infectious disease: the importance of research. Health Risk Soc. 2008;10:349-60.

8. Tang JW, Shetty N, Lam TTY, Hon KL. Emerging, novel, and known influenza virus infections in humans. Infec Dis Clin N Am. 2010;24:603-17.

9. Zimmer SM, Burke DS. Historical perspective - emergence of influenza A(H1N1) viruses. N Engl J Med. 2009;361:279-85.

10. Funk S, Salathe M, Jansen VAA. Modelling the influence of human behavior on the spread of infectious diseases: a review. J R Soc Interface. 2010;7:1247-56. 
11. Reissman DB, Watson PJ, Klomp MOB, Tanielian TL, Prior S. Pandemic influenza preparedness: adaptive responses to an evolving challenge. J Homel Secur Emerg. 2006. doi:10.2202/ 1547-7355.1233.

12. Centers for Disease Control and Prevention. CDC health disparities and inequalities report-United States, 2011. MMWR. 2011;60(suppl):1-114.

13. Institute of Medicine. The 2009 H1N1 influenza vaccination campaign: summary of a workshop series. Washington, DC: The National Academies Press; 2010.

14. Plough A, Bristol B, Fielding J, Caldwell S, Khan S. Pandemics and health equity: lessons learned from the H1N1 response in Los Angeles County. J Public Health Man. 2011;17:20-7.

15. Jones JH, Salathe M. Early assessment of anxiety and behavioral response to novel swine-origin influenza (H1N1). PLoS ONE. 2009;4:1-8.

16. Quinn SC, Kumar S, Freimuth VS, Kidwell K, Musa D. Public willingness to take a vaccine or drug under emergency use authorization during the $2009 \mathrm{H} 1 \mathrm{~N} 1$ pandemic. Biosecur Bioterror. 2009;7:275-90.

17. Bish A, Michie S. Demographic and attitudinal determinants of protective behaviours during a pandemic: a review. Brit J Health Psych. 2010;15:797-824.

18. Leischow SJ, Best A, Trochim WM, Clark PI, Gallagher RS, Marcus SE, et al. Systems thinking to improve the public's health. Am J Prev Med. 2008;35:S196-203.

19. Lindley MC, Wortley PM, Winston CA, Bardenheier BH. The role of attitudes in understanding disparities in adult influenza vaccination. Am J Prev Med. 2006;31:281-5.

20. Santibanez TA, Singleton JA, Santibanez SS. Influenza vaccination during the 2009-10 influenza pandemic: differences in vaccination coverage by race/ethnicity, income, and education. Presentation at American Public Health Association Annual Meeting, November 9, 2010. http://apha.confex.com/ apha/138am/webprogram/Session30094.html. Accessed 15 Dec 2010

21. Viswanath K, Minsky S, Ramamurti D, Kontos EZ. Communication under uncertainty: communication behaviors of diverse audiences during the $\mathrm{A}(\mathrm{H} 1 \mathrm{~N} 1)$ incidence of spring and summer of 2009. Report prepared for the Harvard School of Public Health and the Dana-Farber Cancer Institute; 2009.

22. Holmes BJ, Henrich N, Hancock S, Lestou V. Communicating with the public during health crises: experts' experiences and opinions. J Risk Res. 2009;12:793-07.

23. Linn ST, Guralnik JM, Patel KV. Disparities in influenza vaccine coverage in the United States, 2008. J Am Geriatr Soc. 2010;58:1333-40.

24. Brewer NT, Weinstein ND, Chapman GB, Gibbons FX, Gerard $\mathrm{M}$, McCaul KD, et al. Meta-analysis of the relationship between risk perception and health behavior: the case of vaccination. Health Psychol. 2007;26:136-45.

25. Coelho FC, Codeço CT. Dynamic modeling of vaccinating behavior as a function of individual beliefs. PLoS Comput Biol. 2008;5:1-10.

26. de Zwart O, Veldhujzen IK, Richardus JH, Burg J. Monitoring of risk perceptions and correlates of precautionary behavior related to human avian influenza during 2006-2007 in the Netherlands: results of seven consecutive studies. BMC Infect Dis. 2010;10:114.

27. Weinstein ND, Kwitel A, McCaul KD, Magnan RE, Gerrard M, Gibbons FX. Risk perceptions: assessment and relationship to influenza vaccination. Health Psychol. 2007;20:14651 .

28. Mabry PL, Marcus SE, Clark PI, Leischow SJ, Mendez D. Systems science: a revolution in public health policy research. Am J Public Health. 2010;100:1161-5.
29. Quinn SC. Crisis and emergency communication in a pandemic: a model for building capacity and resilience of minority communities. Health Promot Pract. 2008;9:18S-25.

30. Brewer NT, Weinstein ND, Cuite CL, Herrington JE. Risk perceptions and their relation to risk behavior. Ann Behav Med. 2004;27:125-30.

31. Brug J, Aro AR, Richardus JH. Risk perceptions and behavior: towards pandemic control of emerging infectious diseases. Int $\mathrm{J}$ Behav Med. 2009;16:3-6.

32. Abraham T. Risk and outbreak communication: lessons from alternative paradigms. Bull World Health Organ. 2009;87:604-7.

33. Keller PA, Lehmann DR. Designing effective health communications: a meta-analysis. J Public Policy Mark. 2008;27:11730.

34. Kok G, Jonkers R, Gelissen R, Meetens R, Schaalma H, de Zwart O. Behavioural intentions in response to an influenza pandemic. BMC Public Health. 2010;10:174-93.

35. Leppin A, Aro AR. Risk perceptions related to SARS and avian influenza: theoretical foundations of current research. Int J Behav Med. 2009;16:7-29.

36. Lippke S, Ziegelmann JP. Theory-based behavior change: developing, testing, and applying theories for evidence-based interventions. Appl Psychol-Int Rev. 2008;57:698-716.

37. Maurer J, Uscher-Pines L, Harris KM. Perceived seriousness of seasonal and $\mathrm{A}(\mathrm{H} 1 \mathrm{~N} 1)$ influenzas, attitudes toward vaccination, and vaccine uptake among U.S. adults: does the source of information matter? Prev Med. 2010;51:185-7.

38. Weinstein ND. Testing four competing theories of healthprotective behavior. Health Psychol. 1993;12:324-33.

39. Seale H, Heywood AE, McLaws M, Ward KF, Lowbridge CP, Van D, et al. Why do I need it? I am not at risk! Public perceptions towards the pandemic (H1N1) 2009 vaccine. BMC Infect Dis. 2010;10:99.

40. Slovic P, Finucane ML, Peters E, MacGregor DG. Risk as analysis and risk as feelings: some thoughts about affect, reason, risk, and rationality. Risk Anal. 2004;24:311-22.

41. Setbon M, Raude J. Factors in vaccination intention against the pandemic influenza A/H1N1. Eur J Public Health. 2010;20:490 4.

42. Chapman GB, Coups EJ. Emotions and preventive behavior: worry, regret, and influenza vaccination. Health Psychol. 2006;25:82-90.

43. Ziarnowski KI, Brewer NT, Weber B. Present choices, future outcomes: anticipated regret and HPV vaccination. Prev Med. 2009;48:411-4

44. Farmer P. Social inequalities and emerging infectious diseases. Emerg Infect Dis. 1996;2:259-69.

45. Larson HJ, Heymann DL. Public health response to influenza A (H1N1) as an opportunity to build public trust. J Amer Med Assoc. 2010;303:271-2.

46. Sweeney K. Crisis decision theory: decisions in the face of negative events. Psychol Bull. 2008;134:61-76.

47. Ibuka Y, Chapman GB, Meyers LA, Li M, Galvani AP. The dynamics of risk perceptions and precautionary behavior in response to 2009 (H1N1) pandemic influenza. BMC Infec Dis. 2010;10:296-307.

48. Steelfisher GK, Blendon RJ, Bekheit MM, Lubell K. The public's response to the $2009 \mathrm{H} 1 \mathrm{~N} 1$ influenza pandemic. N Engl J Med. 2010;362:e65-71.

49. Epstein JM. Modelling to contain pandemics. Nature. 2009;460:687.

50. Epstein JM, Parker J, Cummings D, Hammond RA. Coupled contagion dynamics of fear and disease: mathematical and computational explorations. PLoS ONE. 2008;3:e3955.

51. Goodwin R, Gaines SO, Myers L, Neto F. Initial psychological responses to swine flu. Int J Bev Med. 2010. doi:10.1007/s12529010-9083-z. 
52. Liao Q, Cowling BJ, Lam WW, Fielding R. The influences of social-cognitive factors on personal hygiene practices to protect against influenzas: using modeling to compare avian $\mathrm{A} / \mathrm{H} 5 \mathrm{~N} 1$ and 2009 pandemic A/H1N1 influenzas in Hong Kong. Int J Bev Med. 2010. doi:10.1007/s12529-010-9123-8.

53. Wong LP. Knowledge and attitudes about HPV infection, HPV vaccination, and cervical cancer among rural Southeast Asian women. Int J Bev Med. 2010. doi:10.1007/s12529-010-9104-y.
54. Wong LP, Sam I. Knowledge and attitudes in regard to pandemic influenza $\mathrm{A}(\mathrm{H} 1 \mathrm{~N} 1)$ in a multiethnic community of Malaysia. Int J Bev Med. 2010. doi:10.1007/s12529-010-9114-9.

55. Farid-ul-Hasnain S, Krantz G. Assessing reasons for school/ college dropout among young adults and implications for awareness about STDs and HIV/AIDS: findings form a population-based study in Karachi, Pakistan. Int $\mathrm{J}$ Bev Med. 2010. doi:10.1007/s12529-010-9074-0. 